\title{
Model Komunikasi Alternatif dengan Teknologi MANET (Mobile Ad- Hoc Network) untuk Daerah Rural
}

\author{
Alternative Communication Model with MANET (Mobile Ad-Hoc Network) \\ Technology for Rural Areas
}

\author{
Fahrudin Mukti Wibowo $^{1^{*}}$, Iqsyahiro Kresna A $^{2}$, Aditya Wijayanto ${ }^{3}$ \\ Institution/Affiliate Address, Country \\ 1, 2) Informatics Department, Faculty of Informatics \\ Telkom Institute of Technology Purwokerto \\ 3) Software Engineering Department, Faculty of Informatics \\ Telkom Institute of Technology Purwokerto \\ Jl. D.I. Panjaitan, Purwokerto 53147, Indonesia. \\ email: *1fahrudin@ittelkom-pwt.ac.id, ${ }^{2 h}$ hiro@ittelkom-pwt.ac.id, ${ }^{3}$ aditya.wijayanto@ittelkom-pwt.ac.id
}

\author{
DOI; \\ 10.30595/jrst.v5i1.9213
}

Histori Artikel:

Diajukan:

$10 / 12 / 2021$

Diterima:

08/03/2021

Diterbitkan:

$28 / 03 / 2021$

\section{ABSTRAK}

Indonesia merupakan negara kepulauan yang memiliki banyak wilayah yang sulit dijangkau, terutama di daerah perbatasan atau rural. Selain itu ketidaksetaraan distribusi penduduk dan ekonomi membuat pembangunan infrastruktur Teknologi Infomasi dan Komunikasi (TIK) secara keseluruhan di Indonesia tidak merata. Provider penyedia Telekomunikasi dan layanan internet di Indonesia belum dapat memenuhi kebutuhan infrastruktur di daerah terpencil. Solusi komunikasi yang berkembang cepat dan tanpa infrastruktur adalah MANET. MANET adalah sekumpulan node nirkabel yang bekerja sama membentuk jaringan. MANET terbentuk dari sekian banyak host yang terkoneksi melewati router tanpa inftrastruktur yang tetap dan berubah-ubah. Pada pengujian dengan 5 node, kemudian dilakukan analisis QoS dengan standarisasi TIPHON, didapatkan nilai Sangat Bagus Ketika diuji dengan paket 1500 dan 2000 byte mendapatkan nilai indeks lebih dari 3 di Delay, sedangkan Jitter mendapkan nilai Sangat Bagus disemua pengujian dengan nilai indeks diatas 3. Sedangkan Packet Loss mendapatkan nilai Sangat Bagus pada pengujian paket 1000 dengan nilai dibawah 3 , pada pengujian throughput mendapatkan nilai TIPHON Sangat Jelek. Performa MANET dengan routing Babel layak digunakan model komunikasi alternatif karena masih mendapatkan nilai Sangat Bagus pada beberapa pengujian.

Kata Kunci: Model Komunikasi Alternatif, MANET, daerah rural.

\begin{abstract}
Indonesia is an archipelago that has many hard-to-reach areas, especially in the border or rural areas. Besides, inequality in population and economic distribution makes the overall development of the Information and Communication Technology (ICT) infrastructure in Indonesia uneven. Telecommunications and internet service providers in Indonesia have not been able to meet infrastructure needs in remote areas. A communication solution that is growing fast and without infrastructure is MANET (Mobile Ad-Hoc Network). MANET is a set of wireless nodes that work
\end{abstract}


together to form a network. MANET is formed from the many hosts connected through the router without fixed and changing infrastructure. On testing with 5 nodes, then doing a QoS analysis with TIPHON standardization, the value is Very Good when tested with packages of 1500 and 2000 bytes, it gets an index value of more than 3 at the Delay, while in the Jitter gets Very Good value in all tests with an index value above 3. In the Packet Loss gets a Very Good value on the test package 1000 with a value below 3 , while in the throughput testing gets a Very Bad TIPHON value. MANET performance with Babel routing is worth using as an alternative communication model because it still gets Very Good value on some tests.

Keywords: Alternative Communication Model, MANET, rural areas

\section{PENDAHULUAN}

Indonesia merupakan negara kepulauan, memiliki banyak wilayah yang sulit dijangkau, terutama di daerah perbatasan atau rural. Selain itu ketidasetaraan distribusi penduduk dan ekonomi membuat pembangunan infrastruktur Teknologi Infomasi dan Komunikasi (TIK) secara keseluruhan di Indonesia tidak merata. Provider penyedia Telekomunikasi dan layanan internet di Indonesia belum dapat memenuhi kebutuhan infrastruktur di daerah terpencil. Hal lain yang dapat dilakukan untuk mengembangkan pedesaan adalah melalui TIK, namun ada beberapa masalah untuk pembangunan TIK di daerah rural diantaranya:

1. Kurangnya infrastruktur, kendala dalam implementasi infrastruktur adalah wilayah yang kurang strategis dan keterbatasan sumber daya listrik (Kandari \& Pandey, 2015)

2. Budaya, pembangunan di pedesaan atau rural terkendala oleh aturan adat sebuah desa dan budaya tradisional dimana menolak penerimaan ideologi atau teknologi hasil dari globalisasi (Li et al., 2016)

Solusi komunikasi yang berkembang cepat dan tanpa infrastruktur adalah MANET, MANET adalah sekumpulan node nirkabel yang bekerja sama membentuk jaringan (Islam, 2016). Jenis jaringan ini dapat bertahan tanpa adanya infrastruktur yang terhubung (Wang, Yang, Takahashi, Jiang, \& Shen, 2017). Karena node bersifat mobile, kerusakan link mungkin berlangsung pada setiap node tergantung pada pergerakan node. Node dapat berkomunikasi secara multihop, hal ini memungkinkan node yang memiliki jangkauan yang jauh dapat berkomunikasi (Yu, Zhang, Zhou, \& Liu, 2018). MANET memberikan kemampuan komunikasi ke area di mana tidak memadai atau tidak ada infrastruktur komunikasi yang di atur sebelumnya, MANET berkomunikasi tidak menggunkana infrastruktur, komunikasi MANET menggunakan jaringan multihop untuk menawarkan konektivitas yang efektif ( $\mathrm{Wu}$, Yuen, Wang, \& Chen, 2016).

MANET membutuhkan algoritma routing yang handal agar performa dari MANET lebih optimal, sehingga paket - paket data yang dikirimkan dari node utama dapat diterima baik oleh node lainnya, Pada penelitian ini kami menggunakan routing protocol Babel, Babel adalah salah satu protokol routing distance vector yang memiliki performa fast convergence dan fast route repair time (Veselý, Rek, \& Ryšavý, 2019).

Penelitian ini melakukan pemodelan komunikasi alternatif dengan MANET untuk daerah rural, akan dilakukan pengujian performa dari model komunikasi alternatif pada MANET dengan Quality of Service (QoS) sehingga dapat dianalisa kualitas dari komunikasi data pada komunikasi alternatif pada MANET.

\section{METODE PENELITIAN}

MANET terbentuk dari sekian banyak host yang terkoneksi melewati router tanpa inftrastruktur yang tetap dan berubah - ubah (Lego, Singh, \& Sutradhar, 2010). Node pada MANET adalah node yang bergerak, node akan terputus bila ada node yang bergarak diluar area cakupan wifi. Maka dari itu topologi dalam MANET sering berubah dari waktu ke waktu, kategori ini truly mobile ad-hoc network seperti terlihat pada Gambar 1. Gambaran Umum MANET.

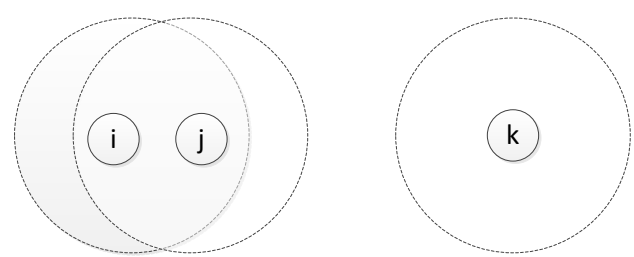

Gambar 1. Gambaran Umum MANET 


\subsection{Analisis Kebutuhan Sistem}

Analisis kebutuhan meliputi kebutuhan perangkat keras dan perangkat lunak.

Analisis Kebutuhan Perangkat Keras

1. Single Board digunakan sebagai node MANET, yang terinstall protokol Babel

2. Micro SDHC V-Gen 16 GB sebagai tempat penyimpanan data dan operating system Raspbian Jessie

3. Power Bank digunakan sebagai sumber daya perangkat Single Board Computer

Analisi Kebutuhan Perangkat Lunak.

1. Routing Protocol

Routing protocol yang aka digunakan yaitu Babel daermon versi 1.1

2. Tools Monitoring Tools yang digunakan untuk mengukur QoS adalah iperf dan ping

3. Babelweb

Tools yang digunakan untuk mapping topologi, menggunakan Babelweb

\subsection{Routing Protocol Babel}

Berikut adalah algoritma dari routing protocol Babel:

1. Deteksi semua link yang terhubung di dalam node

2. Catat semua informasi link ke dalam table routing

3. Tabel routing yang dimiliki masing - masing router akan berisi alamat jaringan yang terhubung langsung dengan router tersebut

4. Secara periodik masing - masing routing saling bertukar informasi sehingga isi table routing terisi lengkap (converged)

5. Jika terjadi perubahan topologi jaringan, maka router akan segera mengupdate informasi routing.

6. Proses update tiap - tiap router dilakukan secara bertahap

7. Jika letak router jauh, maka dalam proses penerimaan informasi tentang perubahan jaringan akan lama pada suatu lokasi.

8. Beritahukan setiap link yang terhubung di dalam node ke node tetangga.

\subsection{Perancangan MANET}

Pada proses ini adalah simulasi terbentuknya MANET, dimana antar node akan saling tersinkronisasi selama berada pada cakupan area signal wireless.

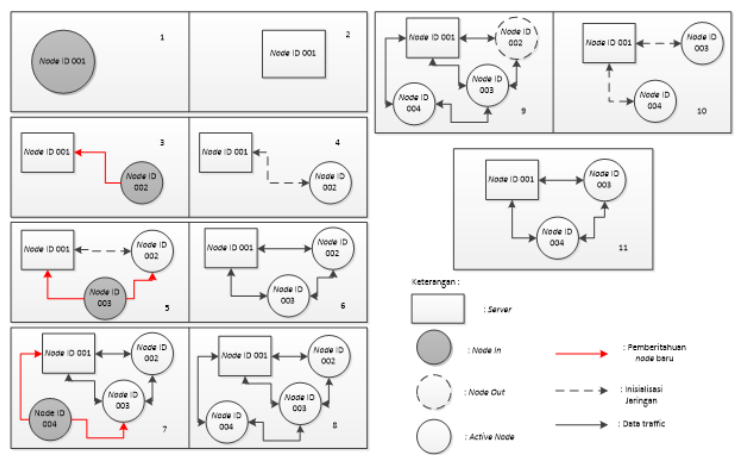

Gambar 2. Ilustrasi Terbentunya MANET.

Setelah node MANET terbentuk, dapat dimonitoring oleh Babelwe, Babelweb adalah interaface yang digunakan untuk memonitoring tampilan dari MANET seperti terlihat pada Gambar 3.

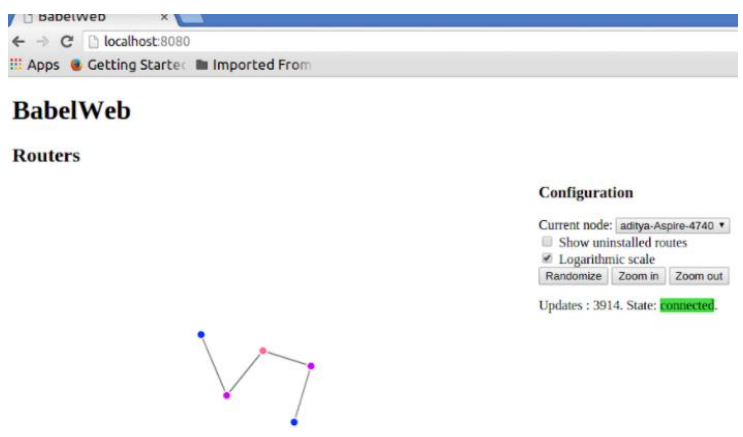

Gambar 3. Interface Topologi MANET.

\subsection{Pengujian QoS}

Pengambilan data pada penelitian ini menggunakan aplikasi monitoring iperf dan ping, pengujian dilakukan pada 5 node.

Tabel 1. Parameter Pengujian QoS

\begin{tabular}{ll}
\hline Komponen & Nilai \\
\hline Durasi pengujian & $5 \mathrm{~s} /$ pengujian \\
Mobility Speed & $1 \mathrm{~m} / \mathrm{s}$ \\
Packet Size & $1000,1500,2000$ \\
& byte \\
Tools & Iperf dan Ping \\
Jumlah Node & 5
\end{tabular}


Untuk mendapatkan nilai QoS akan dilakukan pengambilan data menggunakan iperf, seperti pada Gambar 4. Source code iperf. Ketika dijalankan data - data terkait QoS akan tampil seperti delay, jitter, packet loss, dan throughput.

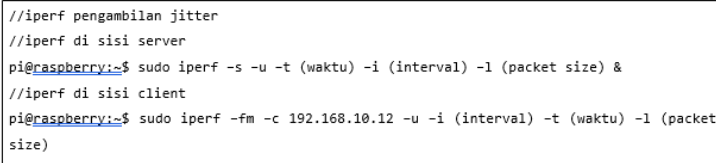

Gambar 4. Source code iperf .

\subsection{Standarisasi QoS}

Merujuk standarisasi penilaian Delay, TIPHON mempunyai nilai standard delay yang ditunjukan apda Table 2. Standarisasi Nilai Delay

Tabel 2. Standarisasi Nilai Delay

\begin{tabular}{ll}
\hline Komponen & Indeks \\
\hline Sangat Bagus & 4 \\
Bagus & 3 \\
Sedang & 2 \\
Jelek & 1 \\
\hline
\end{tabular}

Merujuk standarisasi penilaian Jitter, TIPHON mempunyai nilai standard Jitter yang ditunjukan apda Table 3. Standarisasi Nilai Jitter

Tabel 3. Standarisasi Nilai Jitter

\begin{tabular}{ll}
\hline Komponen & Indeks \\
\hline Sangat Bagus & 4 \\
Bagus & 3 \\
Sedang & 2 \\
Jelek & 1 \\
\hline
\end{tabular}

Merujuk standarisasi penilaian Packet Loss, TIPHON mempunyai nilai standard Packet Loss yang ditunjukan apda Table 4. Standarisasi Nilai Packet Loss.

Tabel 4. Standarisasi Nilai Packet Loss

\begin{tabular}{lll}
\hline Komponen & $\begin{array}{l}\text { Besar } \\
\text { Loss }(\%)\end{array}$ & Packet \\
\hline Sangat Bagus & 0 & \\
Bagus & 3 \\
Sedang & 15 & \\
Jelek & 25 & \\
\hline
\end{tabular}

Merujuk standarisasi penilaian Throughput, TIPHON mempunyai nilai standard
Throughput yang ditunjukan apda Table 5 . Standarisasi Nilai Throughput

Tabel 5. Standarisasi Nilai Throughput

\begin{tabular}{lll}
\hline Komponen & $\begin{array}{l}\text { Besar } \\
(\%)\end{array}$ & Throughput \\
\hline Sangat Bagus & 100 & \\
Bagus & 75 & \\
Sedang & 50 & \\
Jelek & $<25$ & \\
\hline
\end{tabular}

\section{HASIL DAN PEMBAHASAN}

Hasil dapat dianalisa berdasarkan skenario pengujian yaitu 5 node.

\subsection{Pengujian Delay}

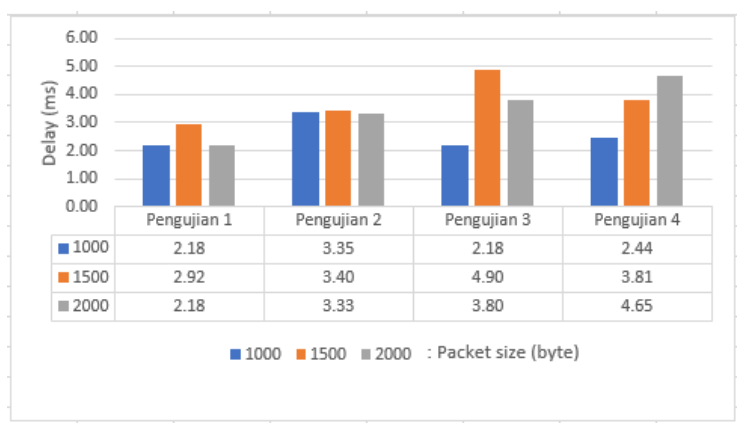

Gambar 5. Grafik rata - rata Delay

Berdasarkan hasil pengukuran pada Gambar 5. Grafik rata - rata Jitter pengujian dengan beban 1000 byte, nilai rata - rata tertinggi dengan nilai $3.35 \mathrm{~ms}$ dan terendah $2.18 \mathrm{~ms}$, dengan beban 1500 byte, nilai tertinggi $4.90 \mathrm{~ms}$, dan terendah $2.92 \mathrm{~ms}$, dengan beban pengujian 2000 byte, nilai rata - rata tertinggi $4.65 \mathrm{~ms}$ dan nilai terendah $2.18 \mathrm{~ms}$.

\subsection{Pengujian Jitter}

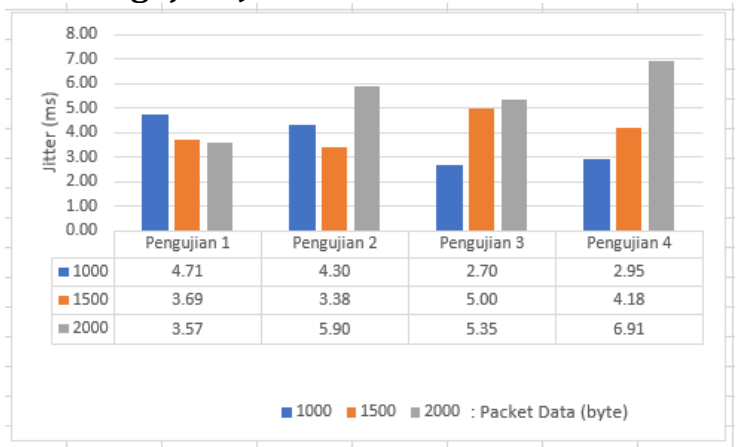

Gambar 6. Grafik rata - rata Jitter 
Berdasarkan hasil pengukuran pada Gambar 6. Grafik rata - rata Jitter pengujian dengan beban 1000 byte, nilai rata - rata tertinggi dengan nilai $4.71 \mathrm{~ms}$ dan terendah $2.30 \mathrm{~ms}$, dengan beban 1500 byte, nilai tertinggi $5.00 \mathrm{~ms}$, dan terendah $3.38 \mathrm{~ms}$, dengan beban pengujian 2000 byte, nilai rata - rata tertinggi $6.91 \mathrm{~ms}$ dan nilai terendah $3.57 \mathrm{~ms}$.

\subsection{Pengujian Packet Loss}

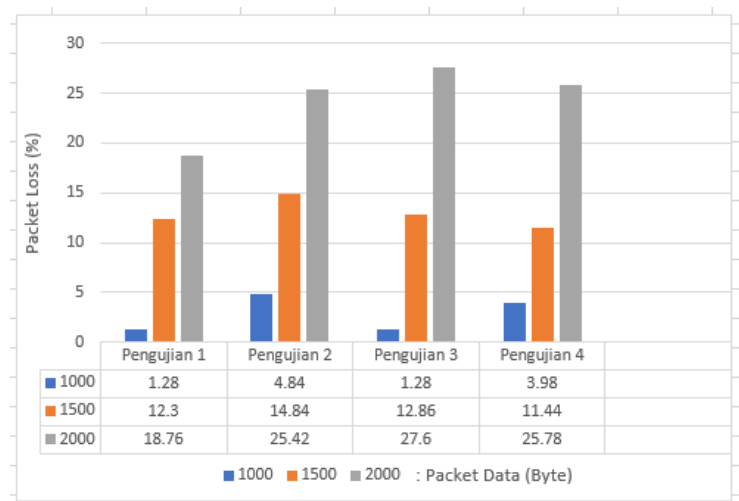

Gambar 7. Grafik rata - rata Packet Loss

Berdasarkan hasil pengukuran pada Gambar 7. Grafik rata - rata Packet Loss pengujian dengan beban 1000 byte, nilai rata rata tertinggi dengan nilai $4.84 \%$ dan terendah $1.28 \%$, dengan beban 1500 byte, nilai tertinggi $14.84 \%$, dan terendah $11.44 \%$, dengan beban pengujian 2000 byte, nilai rata - rata tertinggi $27.6 \%$ dan nilai terendah $18.76 \%$.

\subsection{Pengujian Throughput}

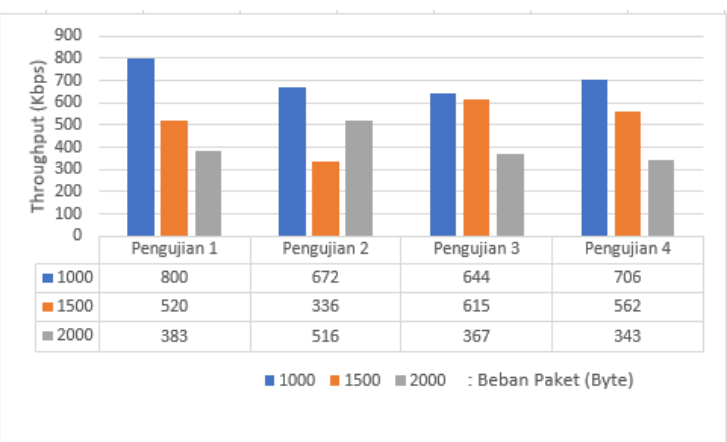

Gambar 8. Grafik rata - rata Throughput

Berdasarkan hasil pengukuran pada Gambar 8. Grafik rata - rata Throughput pengujian dengan beban 1000 byte, nilai rata rata tertinggi dengan nilai $800 \mathrm{Kbps}$ dan terendah $644 \mathrm{Kbps}$, dengan beban 1500 byte, nilai tertinggi
$615 \mathrm{Kbps}$, dan terendah $336 \mathrm{Kbps}$, dengan beban pengujian 2000 byte, nilai rata - rata tertinggi 516 Kbps dan nilai terendah $343 \mathrm{Kbps}$.

\subsection{Analisis Kualitas Standar TIPHON}

Tabel 6. Analisis Kualitas TIPHON

\begin{tabular}{|c|c|c|c|c|}
\hline $\begin{array}{c}\text { Parameter } \\
\text { QoS }\end{array}$ & Skenario & $\begin{array}{l}\text { Beban } \\
\text { Jaringan } \\
\text { (byte) }\end{array}$ & $\begin{array}{c}\text { Rata - rata } \\
\text { nilai } \\
\text { pengujian }\end{array}$ & $\begin{array}{c}\text { Standar } \\
\text { pengujian }\end{array}$ \\
\hline \multirow{3}{*}{ Delay (ms) } & \multirow{3}{*}{5 node } & 1000 & 2.53 & Bagus \\
\hline & & 1500 & 3.75 & $\begin{array}{l}\text { Sangat } \\
\text { Bagus }\end{array}$ \\
\hline & & 2000 & 3.49 & $\begin{array}{l}\text { Sangat } \\
\text { Bagus }\end{array}$ \\
\hline \multirow{3}{*}{ Jitter (ms) } & \multirow{3}{*}{5 node } & 1000 & 3.66 & $\begin{array}{l}\text { Sangat } \\
\text { Bagus }\end{array}$ \\
\hline & & 1500 & 4.06 & $\begin{array}{l}\text { Sangat } \\
\text { Bagus }\end{array}$ \\
\hline & & 2000 & 5.43 & $\begin{array}{l}\text { Sangat } \\
\text { Bagus }\end{array}$ \\
\hline \multirow{3}{*}{$\begin{array}{c}\text { Packet Loss } \\
(\%)\end{array}$} & \multirow{3}{*}{5 node } & 1000 & 2.84 & $\begin{array}{l}\text { Sangat } \\
\text { Bagus }\end{array}$ \\
\hline & & 1500 & 12.86 & Sedang \\
\hline & & 2000 & 24.39 & Jelek \\
\hline \multirow{3}{*}{$\begin{array}{c}\text { Throughput } \\
\text { (Kbps }\end{array}$} & \multirow{3}{*}{5 node } & 1000 & 705.5 & Jelek \\
\hline & & 1500 & 508.2 & Jelek \\
\hline & & 2000 & 402.2 & Jelek \\
\hline
\end{tabular}

Berdasarkan Tabel 6. Analisis Kualitas TIPHON, pada Delay, Jitter, dan Packet Loss memiliki standar TIPHON Sangat Bagus dan Bagus, hanya pada Throughput yang memiliki standarisasi TIPHON jelek.

\section{KESIMPULAN}

Setelah dilakukan pengujian dengan 5 node, kemudian dilakukan analisis QoS dengan standarisasi TIPHON, didapatkan nilai Sangat Bagus Ketika diuji dengan paket 1500 dan 2000 byte mendapatkan nilai indeks lebih dari 3 di Delay, sedangkan Jitter mendapkan nilai sangat bagus disemua pengujian dengan nilai indeks diatas 3. Sedangkan Packet Loss mendapatkan nilai sangat bagus pada pengujian paket 1000 dengan nilai dibawah 3 , pada pengujian throughput mendapatkan nilai TIPHON sangat jelek. Performa MANET dengan routing Babel digunakan sebagai model komunikasi alternatif layak digunakan hal ini dikarenakan masih mendapatkan nilai sangat bagus pada beberapa pengujian. 


\section{UCAPAN TERIMA KASIH}

Ucapan terima kasih diberikan kepada Kemdikbud yang telah memberikan bantuan penelitian melalui program Penelitian Dosen Pemula (PDP)

\section{DAFTAR PUSTAKA}

Islam, S. N. (2016). Achievable Rate And Error Performance of An Amplify And Forward Multi-Way Relay Network In The Presence Of Imperfect Channel Estimation. IET Communications, 10(3), 272-282.

Kandari, S., \& Pandey, M. K. (2015). Impact of Residual Life Estimator Battery Model on QoS Issues in MANET. Wireless Personal Communications, 86(2), 601-614. Springer US.

Lego, K., Singh, P. K., \& Sutradhar, D. (2010). Comparative Study of Adhoc Routing Protocol AODV, DSR and DSDV in Mobile Adhoc NETwork. Indian Journal of Computer Science and Engineering, 1(4), 364-371.

Li, M., Lukyanenko, A., Ou, Z., Ylä-Jääski, A., Tarkoma, S., Coudron, M., \& Secci, S. (2016).
Multipath Transmission for the Internet: A Survey. IEEE Communications Surveys and Tutorials, 18(4), 2887-2925.

Veselý, V., Rek, V., \& Ryšavý, O. (2019). Babel Routing Protocol for OMNeT++ More than just a new simulation module for INET framework.

Wang, W., Yang, B., Takahashi, O., Jiang, X., \& Shen, S. (2017). On the Packet Delivery Delay Study for Three-Dimensional Mobile Ad Hoc Networks. Ad Hoc Networks, 69, 38-48. Elsevier B.V.

Wu, J., Yuen, C., Wang, M., \& Chen, J. (2016). Content-Aware Concurrent Multipath Transfer for High-Definition Video Streaming over Heterogeneous Wireless Networks. IEEE Transactions on Parallel and Distributed Systems, 27(3), 710-723.

Yu, X., Zhang, F., Zhou, L., \& Liu, Q. (2018). Novel Data Fusion Algorithm Based on EventDriven and Dempster-Shafer Evidence Theory. Wireless Personal Communications, 100(4), 1377-1391. Springer US. 